\title{
Maneuver Control System for Collision Avoidance Based on Experimental Study
}

\author{
Kusnindar Priohutomo ${ }^{\text {a*}}$, Agus Achmad Masroeri ${ }^{\mathrm{b}}$, Chandra Permana ${ }^{\mathrm{c}}$ \\ andonesian Hydrodynamics Laboratory, Agency for the Assessment and Application of Technology (BPPT). Email: kusnindar.priohutomo@ gmail.com \\ ${ }^{b}$ Departement of Ship Design Engineering, Institut Teknologi Sepuluh Nopember (ITS). Email: aamasroeri@ its.ac.id \\ 'Indonesian Hydrodynamics Laboratory, Agency for The Assessment and Application of Technology (BPPT).
}

\begin{abstract}
Autopilot mode in the ship navigation system is intended to assist the work of the captain in controlling the ship, but the autopilot mode still has some disadvantages such as in the case of maneuvers to avoid collisions. Many studies on design of anti-collision design. But almost all use a numerical approach. In this paper will be discussed the design of maneuver controls that will be used on the ship model to avoid the ship from the collision. Where within the control system there are several sensors, including ultrasonic sensors, gyro sensors and Qualysis cameras. From ship model testing conducted, the design of maneuver control proved able to avoid the ship from the occurrence of collisions. Minimum distance of ship and obstacle at $250 \mathrm{~m}$ distance is $34.17 \mathrm{~m}$, at a distance of $200 \mathrm{~m}$ is $13.46 \mathrm{~m}$ while at a distance of $150 \mathrm{~m}$ is $13.36 \mathrm{~m}$.
\end{abstract}

Keywords: Collision avoidance; fast patrol boat; microcontroller; model test; system control

\section{Introduction}

The mode of autopilot in the cruise world becomes an important discussion as it helps the seafarers in making it easier to sail the ship. But in autopilot mode itself still has weakness among others in use to avoid collision.

Avoiding collisions is an important issue in transportation systems. The purpose of collision avoidance maneuvers is that ships avoid the risk of collisions and determine actions to avoid or reduce collisions [1].

Much research on the design of controls maneuver to avoid collisions on ships with various methods. Methods ever used among others is manual calculation method, fuzzy logic method and image processing method. Each method has different advantages and disadventages. Some studies releted to avoid ship collisions include reference [2]. The object used in this study is USV (unmanned surface vehicle) in the form of unmanned ships that work automatically according to the program designed. To support the working system USV required several types of sensors such as cameras. The camera works to record the image in front of the ship for further processing by the computer by using the image processing method of HSV Filter, to identify the object and use Fuzzy Logic to

${ }^{\star}$ Coresponding author. Tel.: +62315948060

Jl. Hidrodinamika, Kompleks ITS, Sukolilo Surabaya 60112 determine the angle of the turning of the ship while avoiding the object. From this research, it can be concluded that the ship succeeded in avoiding obstruction objects in all scenarios, to identify the object distance using image processing, the optimal angle of object readings is 750 to 1050 with the average of object coordinate readout error of $0.868 \mathrm{px}$ and the mean error the object's reading angle is $7.450 \%$ cm [3].

Based on research that has done, the conclusion as follows has been done a design of fuzzy logic controller to control the bow and the speed for this type of MT Brotojoyo Tanker which capable of keeping the trajectory in the Port of Tanjung Perak, Surabaya. In the test without disturbance occurs the maximum error of 35.09 meters and a minimum error of 0.9 meters, while in testing with disturbance macimum error value of 35.59 meters and a a minimum error of 0.84 meters. Fuzzy logic system has been designed can increase the efficiency of time sailing 38 minutes [4].

The fuzzy logic control system used is the Sugeno method with nine fuzzy rules. The value of fuzzy output using the weight average method. The control system is designed using a GPS module to determine the position and compass sensor to determine the direction. The conclusion of this research is the design of control system using fuzzy logic controller can control the ship to track the path well. The ship can move at a speed of $0.28 \mathrm{~m} / \mathrm{s}$ and the rudder 
speed is $5.639 \mathrm{~m} / \mathrm{s}$. The compass sensor used has an error of $0.089 \%$. While the GPS module has an average error error of 6.449 meters. The average time it takes is 3.625 seconds.

From several literatures, it is done by using ship model scale test method in the basin of maneuver testing. For the purposes of testing it is necessary to design the proper maneuver control so that the ship can avoid the collision. The use of microcontroller and some sensors such as ultrasonic sensors to detect the distance of the ship with obstacles, gyro sensors to know the movement of ship yaw, servo rudder to know the movement of ship rudder and Qualysis camera to know the trajectory between the ship and obstacles

\section{Experiment Method}

The research methodology was developed to produce a technically good maneuver control design, in which the steps in the methodology can be described as follows:

\subsection{Main dimension}

First determine the main dimension of the ship which is an important factor in ship designing. The ship model used follows Fast Patrol Boat, where the main dimension between real scale and model scale to be used in research can be seen in Table 1 .

\subsection{Collision avoidance control system equipment}

\subsubsection{Arduino Mega 2560}

Arduino Mega 2560 is a microcontroller board based on Atmega 328. This board has 54 digital input/output pins (14 pins can be used as PWM output), 16 analog inputs. 16 $\mathrm{MKz}$ crystal oscillator, USB connection, power jack, ICSP header and reset button, as shown in Fig. 1.

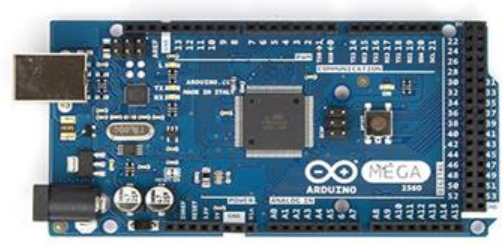

Figure 1. Microcontroller Arduino Mega 2560

Table 1. Main dimension.

\begin{tabular}{cccc}
\hline No & Symbol & Rate Scale & Model Scale \\
\hline 1 & LOA & $90 \mathrm{~m}$ & $1.27 \mathrm{~m}$ \\
\hline 2 & LWL & $86.45 \mathrm{~m}$ & $1.22 \mathrm{~m}$ \\
\hline 3 & Breadth & $13 \mathrm{~m}$ & $0.185 \mathrm{~m}$ \\
\hline 4 & Draught & $3.6 \mathrm{~m}$ & $0.051 \mathrm{~m}$ \\
\hline 5 & Displacement & $1700 \mathrm{ton}$ & $4.66 \mathrm{~kg}$ \\
\hline 6 & LCB & $0.54 \% \mathrm{LPP}$ & \\
\hline 7 & Service Speed & $18 \mathrm{knot}$ & $1.1 \mathrm{~m} / \mathrm{s}$ \\
\hline 8 & Top Speed & $28 \mathrm{knot}$ & $1.71 \mathrm{~m} / \mathrm{s}$ \\
\hline 9 & Propeller & $3.3 \mathrm{~m}$ & $0.047 \mathrm{~m}$ \\
\hline
\end{tabular}

\subsubsection{Ultrasonic sensor}

The ultrasonic sensor used is a non-contact distance measuring module shown in Fig. 2. To trigger and read the measurement data requires only 1 pin microcontroller. In addition provided $12 \mathrm{C}$ communication interface.

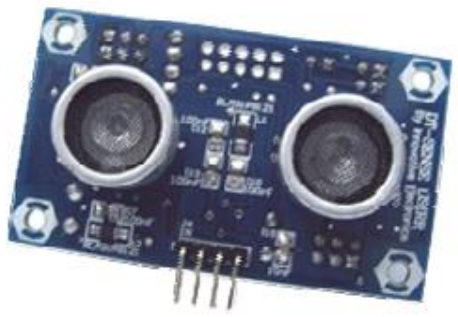

Figure 2. Ultrasonic sensor

\subsubsection{IMU sensor}

The inertial measurements unit (IMU) is shown in Fig. 3 as an inertial component used to guide a system commonly used in ground vehicles, marine vehicles, and control rockets. The IMU sensor works by sensing a movement, and the directional displacement using a combination of accelerometer sensor is used to determine the acceleration of gravity, gyroscopes are used to determine angular acceleration and the magnetometer sensor is used for heading or determining the direction of the wind and is used as a reference to the yaw axis.

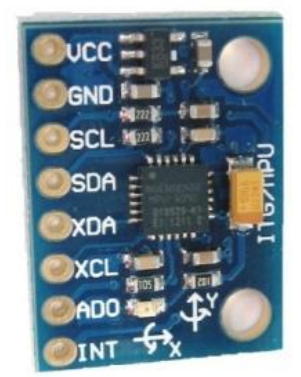

Figure 3. IMU sensor GY-521

\subsubsection{Radio Telemetry}

Radio telemetry shown in. Fig. 4 is a hardware that serves to transmit data using wirelesscommunication system.

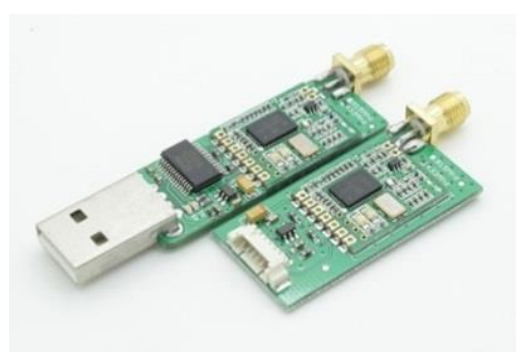

Figure 4. Radio Telemetry $433 \mathrm{Mhz}$ 


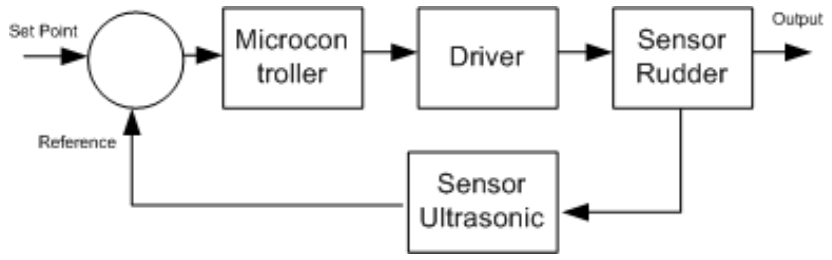

Figure 5. Ultrasonic sensor block diagram [5]

\subsection{Design of control system}

\subsubsection{Ultrasonic sensor design model test}

In the ultrasonic sensor book manual of Elecfreaks [5], the design of ultrasonic sensors serves to know and measure the distance of the model with a obstacle.

In the design of ultrasonic sensors, block diagram in Fig. 5 and wire communication in Fig. 6 are used by connecting Vcc, Gnd, Echo and trigger pins.

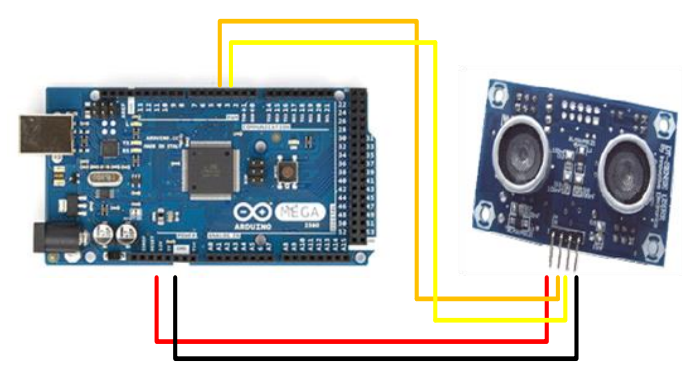

Figure 6. Design of ultrasonic sensor

To avoid the ship from collision, the ultrasonic sensor is set as listed in Table 2.

Table 2. Ultrasonic sensor setting

\begin{tabular}{ccc}
\hline No & $\begin{array}{c}\text { Distance of the Collision } \\
(\mathrm{m})\end{array}$ & $\begin{array}{c}\text { Sensor Setting } \\
(\mathrm{m})\end{array}$ \\
\hline 1 & 250 & 285 \\
\hline 2 & 200 & 235 \\
\hline 3 & 150 & 185 \\
\hline
\end{tabular}

\subsubsection{IMU sensor design model test}

According to the manual book of IMU Sensor [6], the design of gyro sensor serves to know and measure changes in heading angle yaw model of the ship.

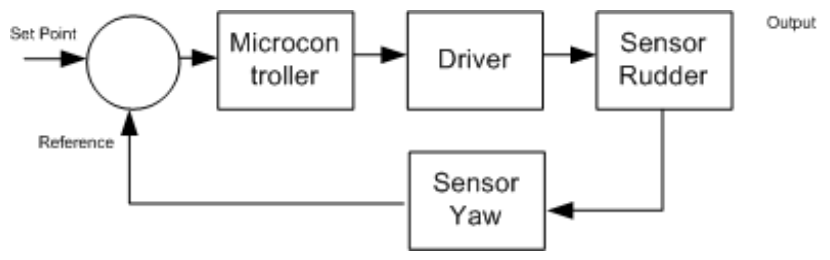

Figure 7. IMU sensor block diagram
The design of the gyro sensor uses block diagram in Fig. 7 and i2c serial data communication by connecting Vcc, Gnd, SDA, SCl and INT, as illustrated in Fig. 8.

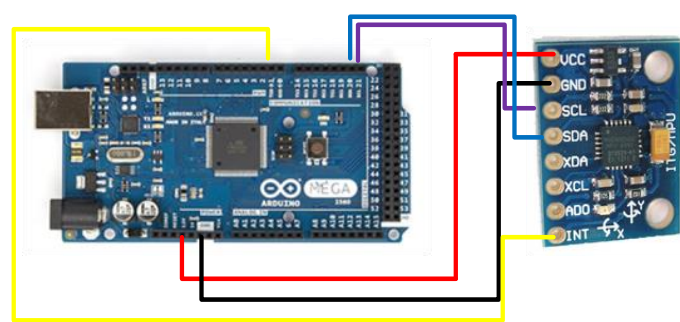

Figure 8. Design of IMU sensor

\subsubsection{Servo rudder design model test}

The design of servo rudder in Fig. 9 serves to know and measure the angle change rudder model ship. The design of servo rudder using PWM (Pulse Width Modulation) method. With PWM method can be generated servo movement is quite accurate with the desired resolution.

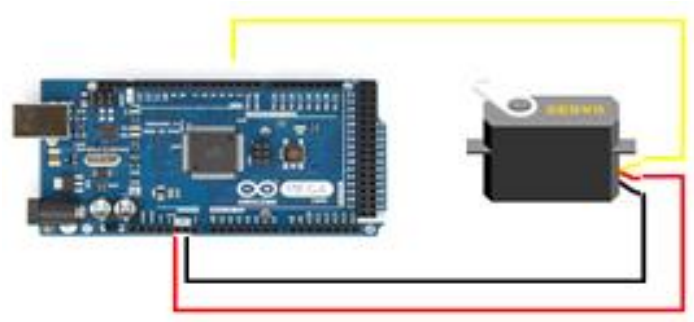

Figure 9. Design of servo rudder

\subsubsection{Radio telemetry design model test}

In the Advanced Telemetry System manual book [7], telemetry radio design on the test model in Fig. 10 serves to transmit raw data information changes yaw model ship to the system ground station with realtime.

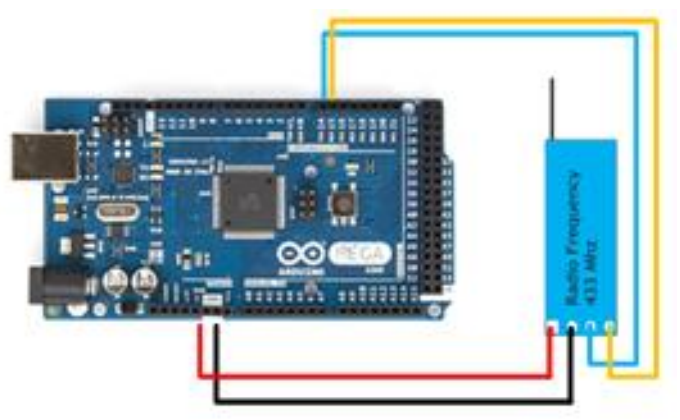

Figure 10. Design of radio telemetry

\subsection{Trajectory model measurement system}

Measurement of trajectory model movement during the test was performed using QTM (Qualisty Track Manager) equipment. QTM is a software designed using Qualisys camera model, the camera is used as a medium of fast and precise data collection. This system allows users to record data in real time both in $2 \mathrm{D}, 3 \mathrm{D}$ and $6 \mathrm{DOF}$ with fast 


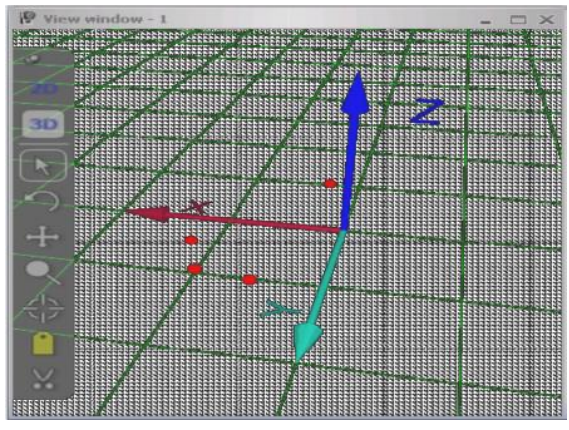

Figure 11. QTM

response time [8]. QTM can also identify marker automatically either passive or active marker, easy in addition of camera if necessary expansion of area object that is recorded. Figure 11 shows the coordinate system on the display.

At the time of capture measurement implemented software will immediately record marker movement (if no setting delay) and can be displayed preview of measurement with preview button. For the sampling rate of the measurement itself can be adjusted from the capture period. The results of the QTM calibration can be seen in Fig. 12. Where the red dot is the marker of the ship that has been installed the Qualisys marker, whereas the $\mathrm{x}, \mathrm{y}$ and $\mathrm{z}$ axis each represent the axis present in the test basin.

\subsection{Scenario testing}

The test scenario in this study follows the pattern of COLREG 72. COLREG 72 has arranged scenarios to avoid collisions in accordance with the position of the ship, including head-on position, crossing position and overtaking (the ship behind will precede the ship in front). Of the three scenarios according to COLREG 72 which will be used in this research is the head-on scenario (ship facing). Where the two ships will do the steering wheel (rudder) to the starboard (right). So the ship can avoid the collision.

In this study the speed of the ship is made constant at 10 knots. While the speed of the ship obstacle at 2 knots. Model test conducted at Manauvering Ocean Basin (MOB) where basin test fasilities belongs Indonesian Hydrodynamics Laboratory - BPPT Surabaya, in calm water condition (non disturbance).

Variations that are done is the distance of the ship with the obstacle (the distance of the collision) that is 250 meters, 200 meters and 150 meters. Tests on each variation of the distance of the ship against the obstruction are done as much as $3 \mathrm{x}$ in order to be taken on average.

\section{Results Analysis and Discussion}

\subsection{Ship and obstacle trajectory}

From the test results by using Qualysis camera, the ship trajectory graphic ( $x$ axis, $y$-axis) at $250 \mathrm{~m}, 200 \mathrm{~m}$ and 150 $\mathrm{m}$.
Ship Model and Ship Obstacle Trajectory

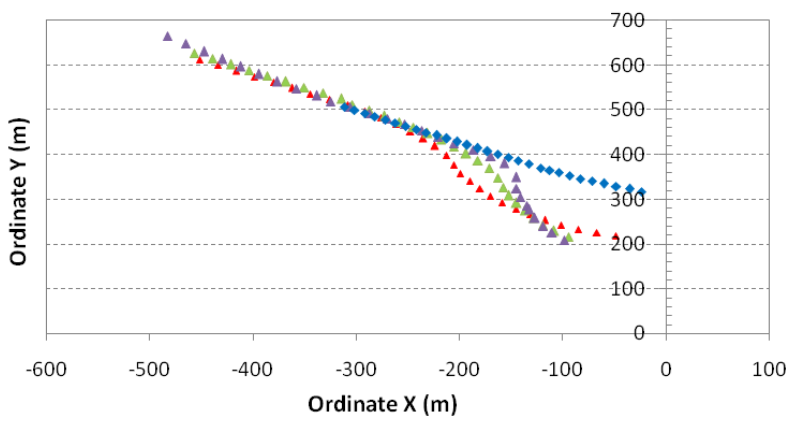

$\Delta$ Ship Trajectory $250 \mathrm{~m}$ ॥ Ship Trajectory $200 \mathrm{~m}$

$\triangle$ Ship Trajectory $150 \mathrm{~m}$ - Ship Obstacle

Figure 12. Ship and obstacle at distance of collision $250 \mathrm{~m}, 200 \mathrm{~m}$ and $150 \mathrm{~m}$

\subsection{Distance from ship to obstacle}

From the trajectory of the ship and the obstacle in Fig. 12, we can find the distance between the two points of the ship's trajectory point ( $x$-axis, $y$-axis) and the point of the obstacle ( $x$-axis, $y$-axis). The $z$-axis on the ship and the obstacle is not counted because during the test the ship moves on the axis of the $2 \mathrm{D}$ axis is the $\mathrm{X}$ and $\mathrm{Y}$ axis. The formula for finding two points is as follows:

$$
\begin{aligned}
\text { Distance } & =\sqrt{\text { difference } x^{2}+\text { difference } y^{2}} \\
& =\sqrt{\left(x_{2}-x_{1}\right)^{2}+\left(y_{2}-y_{1}\right)^{2}}
\end{aligned}
$$

Where:

$$
\begin{array}{ll}
x_{1} & =\text { Value X Obstacle } \\
x_{2} & =\text { Value X Ship } \\
y_{1} & =\text { Value Y Obstacle } \\
y_{2} & =\text { Value Y Ship }
\end{array}
$$

From Eq. 2, we can calculate the distance between the two points that is $x$-axis, $y$-axis of the ship's trajectory and $x$-axis, $y$-axis obstacle at $250 \mathrm{~m}, 200 \mathrm{~m}$ and $150 \mathrm{~m}$. The results shown in Fig. 13.

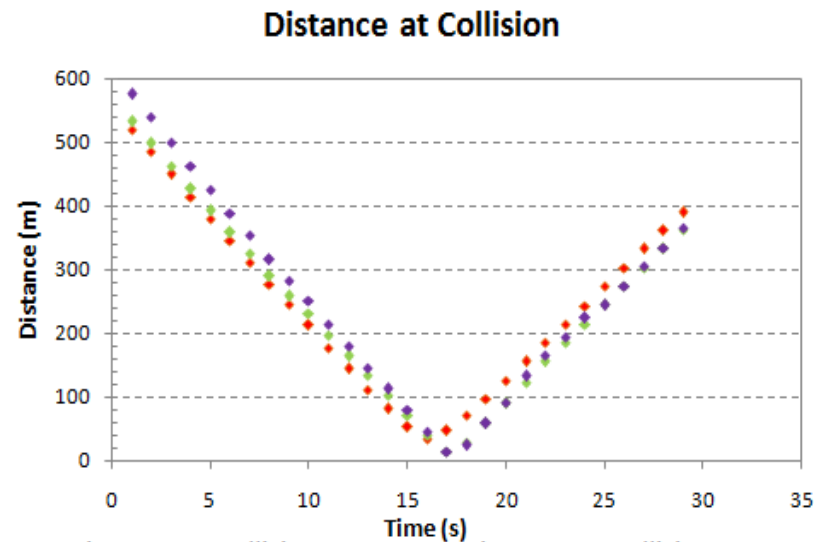

- Distance at Collision 250 m - Distance at Collision 200 m

- Distance at Collision 150 m

Figure 13. Distance from ship and obstacle at distance of collision $250 \mathrm{~m}, 200 \mathrm{~m}$ and $150 \mathrm{~m}$ 


\section{Conclusion}

From the results of measurement and analysis of test results it can be taken a conclusion. Based on the experimental results it is found that the design of maneuver controls installed in the model of fast patrol boats during the test, may prevent the ship from occurring collisions.

Ships at 10 knots can avoid collisions at $250 \mathrm{~m}, 200 \mathrm{~m}$ and $150 \mathrm{~m}$ in non-disturbance conditions. The closest distance between the ship and the obstac le at a distance of $250 \mathrm{~m}$ is $34.17 \mathrm{~m}$ at $\mathrm{T}=16$ seconds, at a distance of $200 \mathrm{~m}$ is $13.46 \mathrm{~m}$ at $\mathrm{T}=17$ seconds and at a distance of $150 \mathrm{~m}$ is $13.36 \mathrm{~m}$ at time $\mathrm{T}=17$. This distance is obtained when the ship is adjacent or side by side with obstacles.

\section{References}

[1] L. P. Perera, J. P. Carvalho, and C. . Guedes Soares, "Autonomous Guidance and Navigation Based On The COLREGs Rules and
Regulations of Collision Avoidance.," Adv. Sh. Des. Pollut. Prev., no. 1999 , pp. 205-216, 2010.

[2] M. Iqbal, R. Nugraha,"Design Boat Control System for Collision Avoidance," e-Proceeding Universitas Telkom, vol. 4, no. 2, pp. 1426-1433, 2017.

[3] A. S. Aisjah, A. A. Masroeri, M. A. Efendi, E. B. Djatmiko, W. D. Ariyawan, and F. A. Iskandarianto, "Fuzzy Control for Optimizing Ship Tracking in Karang Jamuang - Tanjung Perak," The Journal for Technology and Science, vol. 23, no. 4, pp. 118-125, 2012.

[4] M. Ridwan, A. S. Aisjah, "Prototype Design of Control Systems Tracker Tracks on Unmanned Vessel Using Fuzzy Logic,” Jurnal Teknik. Elektro ,no. 1, pp. 1-8. 2014.

[5] E. Freaks, "HC-SR04 User Guide," Elec. Freaks, pp. 1-6, 2011.

[6] Studuino, "Studuino Gyroscope." Environment and Software, pp. 1$15,2012$.

[7] Ats, "Advanced Telemetry Systems - Manual Tracking," pp. 1-5, 2009.

[8] A. Fallis, "Qualisis pdf," J. Chem. Inf. Model., vol. 53, no. 9, pp. 1689-1699, 2013.

[9] IMO, "COLREGS - International Regulations for Preventing Collisions at Sea," Conv. Int. Regul. Prev. Collisions Sea, 1972, pp. 1-74, 1972. 